\title{
The Big Mistake of not Considering Physical Activity an Essential Element of Care During the Covid-19 Pandemic
}

Francisco José Gondim Pitanga, ${ }^{\circledR}$ Carmem Cristina Beck, ${ }^{2}{ }^{\circledR}$ Cristiano Penas Seara Pitanga ${ }^{3}$

Universidade Federal da Bahia,' Salvador, BA - Brazil.

Instituto Federal de Santa Catarina, ${ }^{2}$ Florianópolis, SC - Brazil.

Universidade Católica do Salvador, ${ }^{3}$ Salvador, BA-Brazil.

\section{Reply}

\section{Dear Editor,}

In response to the letter to the editor entitled "Declaring physical activity as 'essential' during the Covid-19 pandemic may not be a good measure" ${ }^{1}$ that presented contributions to our point of view entitled "Should physical activity be considered essential activity during the Covid-19 pandemic?"2 we thank you for the suggestions and we present a reply letter with our arguments:

Although the benefits of physical activity for the cardiovascular, metabolic, immune systems, as well as for mental health are very well documented in the literature, ${ }^{3,4,5}$ the discussion about physical activity is considered essential during the new coronavirus pandemic remains with different positions on the part of the researchers.

The main source of disagreement seems to be about the greater probability of infection when practicing physical activity in open environments or in fitness centers, a fact that lacks scientific proof. The study cited by the authors of the letter to the editor, about contamination by the new coranavirus in dance studios, was carried out

\section{Keywords}

COVID-19, Betacoronavirus, Exercise; Pandemics; Hospitalization; Physical Activity; Quality of Life; Epidemiology. at the beginning of the pandemic, when the biosafety protocols currently adopted did not exist, both for outdoor activities and for fitness centers. ${ }^{6}$

From a political point of view, which seems to be the main source of argument for the authors of the letter to the editor, we clarify that since February 2020, the Federal Government of Brazil published law no 13,979, of February 6, 2020, which provides for measures to facing the public health emergency of international importance resulting from the coronavirus responsible for the 2019 outbreak, a fact that leads us to believe that all necessary measures have been taken to face the pandemic.

Specifically with regard to physical activity, both the Federal Government of Brazil and the Legislative Assembly of the State of Santa Catarina, Brail, published documents regarding physical activity as essential during the pandemic. In the case of the state of Santa Catarina, law no 17941 of 05/08/2020 was published and the Federal Government, Decree $n^{\mathrm{o}}$ 10,344, of May 11, 2020 was published.

It is important to note that in the case of the state of Santa Catarina, despite the law that considered physical activity as essential, having been published in the beginning of May 2020, its capital Florianópolis, it remains among the Brazilian capitals that it presents in relation to too, small number of deaths, as well as low lethality of the disease. It is noteworthy that in this capital, since the enactment of the state law, public spaces were released for physical activity and the fitness centers were opened so that people could attend them, obviously following strict biosafety protocols.

On the other hand, as we have a recent disease, specific

Mailing Address: Francisco José Gondim Pitanga

Av. Reitor Miguel Calmon, s/n. Postal Code: 40110-060, Vale do Canela,

Salvador, BA - Brazil.

E-mail: pitanga@lognet.com.br 
studies on physical activity as a protective factor for mortality due to Covid-19, as well as on the worsening of the clinical picture are still scarce, despite the fact that the first published recently of them when it was demonstrated that physical activity was a protective factor for hospitalizations due to the new coronavirus, despite the information on lifestyle having been collected in $2010 .^{7}$

Another more recent study carried out in 45 African countries demonstrated an association between physical inactivity and mortality due to Covid-19. It is noteworthy that the association was observed only in accumulated deaths, not remaining statistically significant when deaths were adjusted per million inhabitants ${ }^{8}$.

It is important to note that despite the scarcity of studies on physical activity and Covid-19, there are several studies that demonstrate that physical activity

\section{References}

1. Almeida RT, Queiroz CO, Aquino EML. Declaring Physical Activity as 'Essential' During the COVID-19 Pandemic May not be a Good Measure. Int. J. Cardiovasc. Sci. 2020; 33(5): 589-590.

2. Pitanga FJG, Beck CC, Pitanga CPS. Should Physical Activity Be Considered Essential During the COVID-19 Pandemic?. Int. J. Cardiovasc. Sci. 2020; 33(4): 401-403.

3. Lin X, Alvim SM, Simoes EJ, Bensenor IM, Barreto SM, Schmidt MI, et al. Leisure time physical activity and cardio-metabolic health: results from the Brazilian Longitudinal Study of Adult Health (ELSA-Brasil). J Am Heart Assoc. 2016;5(6):pii003337.

4. Krinski K, Elsangedy HM, Colombo H, Buzzachera CF, Soares IA, Campos W, Silva SG. Physical exercise effects in the immunological system. Rev Bras Med. 2010;67(7):227-8.

5. Mammen G, Faulkner G. Physical activity and the prevention of depression: a systematic review of prospective studies. Am J Prev Med. 2013;45(5):649-57.

6. Cortez, ACL, Pitanga FJG, Santos MAA, Nunes RAM, Rosas DAB, Dantas EHM, Centers of physical activities and health promotion during the covid-19 pandemic Rev. Assoc. Med. Bras. 2020; 66(10): 1328-1334. can influence the reduction of the worsening of the clinical picture and mortality, as well as positively, in the effects of vaccination in relation to influenza/H1N1, with different authors suggesting that these results can be transported to Covid-19, since these are pandemics with similar viral characteristics. ${ }^{9,10}$

Thus, in our view, physical activity should be considered essential during the pandemic of the new coronavirus. We go even further, suggesting that the increase in the practice of physical activity by the population may make us better prepared not only for the current pandemic, but also for future ones that may come to affect us. Therefore, we insist on suggesting to our government officials that they consider physical activity as an essential activity in any legal determination that may be published.

7. Hamer M, Kivimäki M, Gale CR, Batty GD. Lifestyle risk factors, inflammatory mechanisms, and COVID-19 hospitalization: A community-based cohort study of 387,109 adults in UK. Brain Behav Immun. 2020; 87: 184-187. doi:10.1016/j.bbi.2020.05.059.

8. Okeahalam C, Williams V, Otwombe K. Factors associated with COVID-19 infections and mortality in Africa: a cross-sectional study using publicly available data. BMJ Open. 2020;10(11):e042750. doi: 10.1136/bmjopen-2020-042750.

9. Wong CM, Lai HK, Ou CQ, et al. Is exercise protective against influenzaassociated mortality? PLoS One. 2008;3(5):e2108. doi:10.1371/journal. pone.0002108.

10. Woods JA, Keylock KT, Lowder T, et al. Cardiovascular exercise training extends influenza vaccine seroprotection in sedentary older adults: the immune function intervention trial. J Am Geriatr Soc. 2009;57(12):21832191. doi:10.1111/j.1532-5415.2009.02563. 